treatment week $(p=0.001)$ which persisted for three weeks $(\mathrm{p}=0.001)$. Group based trajectory modelling indicated that $15 \%$ of patients showed a temporary increase in white cell and neutrophil trajectories. Logistic regression revealed that treatment response was not associated with a 'spike' in cell count. However, females were 2.08 times more likely to respond to treatment $(95 \%$ CI $[1.09,4.08], p=0.017)$ and 2.67 times more likely to exhibit a 'spike' in cell counts following Clozapine initiation (95\% CI [1.14, 6.24], $\mathrm{p}=0.023$ ).

Conclusions This is the first study to examine whether Clozapine's immunomodulatory properties contribute towards its unique efficacy. We found that clozapine was associated with an early 'spike' in all cell lines. Further analysis revealed a relatively small portion of patients were responsible for this transient increase. Increased cell counts did not predict Clozapine response at three months, but gender was implicated as a potential moderator variable.

\section{A MULTI-SPECIALITY CONUNDRUM: NEUROPSYCHIATRIC SEQUELAE OF THYROTOXICOSIS}

Lori Black*. Cardiff and the Vale University Healthboard

\subsection{6/jnnp-2019-BNPA.40}

A 51 year old man with bipolar affective disorder and an extensive forensic history was admitted informally to the forensic low secure inpatient unit for alcohol detoxification and to establish more effective long-term community management. 3 weeks into the admission his presentation abruptly changed. He would have prolonged periods of unresponsiveness, lasting hours to days, where he would lie in bed or stand rigidly with no vocal response to commands or questions. These were interspersed by periods where he would become agitated, pacing the wards, urinating and defecating in public spaces. This could last several hours and required rapid tranquilisation regularly.

On examination in his stupor, he was seen to be lying in bed with his eyes closed, opening them a fraction to voice. He was sometimes able to follow simple commands but this was slow and inconsistent. He was unable to communicate through head movements or blinking and stared with a fixed expression. There was waxy flexibility of his limbs and arching on the back at regular intervals. Power was normal with flexor plantars. There were no ictal signs (i.e. no nystagmus/gaze deviation/twitching/ dystonia). When agitated he was seen to have echopraxia. He consistently had hyperhydrosis and tachycardia.

Bloods showed an elevated T4 (22.7) with a suppressed TSH $(<0.01)$ and a normal T3. TSH receptor and thyroid peroxidise antibodies were positive. A CT head was normal. Channel and receptor antibodies were normal.

It was felt that the patient had developed catatonia secondary to thyrotoxicosis due to his underlying neuropsychiatric susceptibility. He was treated effectively with high dose lorazepam as per the Maudsley Guidelines along with olanzapine $(20 \mathrm{mg})$ and sodium valproate, which was used as an alternative to lithium. The thyrotoxicosis was effectively treated with carbimazole and the patient made a good recovery.

Hyperthyroidism is a rare but recognised cause of psychosis and multiple case reports have demonstrated an association between thyrotoxicosis and catatonic states. In this case report, it is probable that the patient's underlying bipolar affective disorder made him more susceptible to developing neuropsychiatric features as a consequence of his thyrotoxicosis. However, this is particularly pertinent given that lithium, the most evidence-based treatment for bipolar affective disorder, has potential to disrupt thyroid function.

\section{KORSAKOFF'S SYNDROME: NEUROCOGNITIVE DOMAINS IMPAIRMENTS AND POTENTIAL THERAPEUTIC INTERVENTIONS}

1,2 J Hoblyn*, Tayler Sulse, Emma Mae Huston, Melanie Ryberg, P Byrne, Kieran O'Driscoll. ${ }^{1}$ Bloomfield Health Services; ${ }^{2}$ Trinity College Dublin, Republic of Ireland; ${ }^{3}$ University California Berkeley, USA

\subsection{6/jnnp-2019-BNPA.41}

Objectives/aims To explore the burden of neurocognitive impairments in a cohort of Individuals with Korsakoff's psychosis requiring current long stay psychiatric care. To consider additional therapeutic interventions to target the health care burden potentially created by these comorbidities.

\begin{tabular}{|c|c|c|c|c|c|c|c|}
\hline $\begin{array}{l}\text { Patient } \\
\text { Number }\end{array}$ & $\begin{array}{l}\text { Complex } \\
\text { Attention }\end{array}$ & $\begin{array}{l}\text { Executive } \\
\text { Function }\end{array}$ & $\begin{array}{c}\text { Learning and } \\
\text { Memory }\end{array}$ & Confabulation & Language & $\begin{array}{l}\text { Perceptual } \\
\text { Motor }\end{array}$ & $\begin{array}{c}\text { Social } \\
\text { Cognition }\end{array}$ \\
\hline 1 & $x$ & $x$ & $x$ & $x$ & & $x$ & $x$ \\
\hline $2^{*}$ & $x$ & $x$ & $x$ & & & $x$ & $x$ \\
\hline 3 & $\mathrm{x}$ & $x$ & $x$ & $x$ & & & \\
\hline 4 & $x$ & $x$ & $x$ & & & $x$ & $x$ \\
\hline $5^{*}$ & $x$ & $x$ & $x$ & $x$ & & $x$ & $x$ \\
\hline 6 & & $x$ & $x$ & $x$ & & & \\
\hline 7 & $x$ & $x$ & $x$ & & & & $x$ \\
\hline $8^{*}$ & $x$ & $x$ & $x$ & $x$ & $x$ & $x$ & $x$ \\
\hline 9 & $x$ & $x$ & $x$ & $x$ & $x$ & & \\
\hline 10 & & & $x$ & & $x$ & & \\
\hline 11 & $x$ & $x$ & $x$ & & & & \\
\hline 12 & & $x$ & $x$ & $x$ & & & $x$ \\
\hline $13^{* *}$ & $x$ & $x$ & $x$ & & $\mathrm{x}$ & $x$ & \\
\hline
\end{tabular}

